\title{
Impact of obstructive airways disease on quality of life in older adults
}

\author{
Deborah S Renwick, Martin J Connolly
}

\begin{abstract}
Background - Obstructive airways disease adversely affects quality of life, although relationships between quality of life and lung function have been shown to be weak. The relationships between the results of a quality of life questionnaire, spirometric tests, and methacholine bronchial challenge were investigated in a population sample of middle aged and elderly people. Methods - A random population sample of the white population of Central Manchester, UK were contacted by post. Respondents were invited to undergo bronchial challenge with methacholine (Newcastle dosimeter method) and to complete the St George's Respiratory Questionnaire. This self-completed questionnaire quantifies quality of life as three component scores, with higher scores indicating greater impairment of quality of life.
\end{abstract}

Results - Two hundred and twenty seven subjects aged 45-86 years completed the St George's Questionnaire and performed spirometric tests; 190 completed the methacholine challenge. All quality of life scores were higher in subjects with a forced expiratory volume in one second $\left(F_{E V}\right)$ ) forced vital capacity (FVC) of $<65 \%$, indicating impaired quality of life in subjects with airways obstruction. There was no relationship between quality of life and age. Multiple regression analysis showed independent relationships between quality of life scores and both baseline $F E V_{1}$ and bronchial responsiveness. However, the amount of variation in quality of life attributable to variation in $F_{1} V_{1}$ or bronchial responsiveness was less than $10 \%$. Subgroup analysis indicated that the quality of life score was independently associated with bronchial responsiveness and not $F E V_{1}$ in subjects aged $<65$ years, but with baseline $F E V_{1}$ and not bronchial responsiveness in older subjects.

Conclusions - Obstructive airways disease significantly impairs quality of life in adults. The reduction in quality of life in these patients is related to both baseline pulmonary function and non-specific bronchial responsiveness. The impact of airways obstruction on quality of life does not decrease with advancing age.

(Thorax 1996;51:520-525)

Keywords: quality of life, chronic airways obstruction, bronchial hyperresponsiveness.
Obstructive airways disease is common in the elderly, affecting approximately $16 \%$ of people over the age of $65 .^{1}$ It has a substantial impact on quality of life, impairing not only physical, but also psychological and social function. ${ }^{23}$ The relationship between the degree of quality of life impairment and the severity of airways obstruction as measured by pulmonary function tests has, however, generally been found to be weak. ${ }^{2-5}$

It has been suggested that the impact of obstructive airways disease on quality of life may be less in older subjects. ${ }^{356}$ We have therefore compared the quality of life in subjects with and without chronic airways obstruction and bronchial hyperresponsiveness to assess the effects of chronic obstructive airways disease and asthma on quality of life in a population sample of adults aged 45-86 years.

\section{Methods}

Names of adults aged $\geq 45$ were taken using random number tables from practice lists of 22 local general practitioners. Those who were confused or housebound were excluded, together with the few unsuitable for other reasons. Non-white subjects were excluded because of interracial differences in bronchial responsiveness. $^{7}$

Subjects were sent an explanatory letter and questionnaire concerning previous asthma, bronchitis, ischaemic heart disease, smoking history, and current medication. Non-responders were sent a reminder, followed by a second reminder with an abbreviated questionnaire. A random sample of persistent nonresponders was contacted by telephone or home visit.

Questionnaire responses were used to identify those excluded from methacholine challenge. Exclusion criteria were ischaemic heart disease or medication with $\beta$ blockers, anticholinergics or oral steroids. Subjects not excluded on this basis were invited to attend. Attendance was delayed for six weeks after a respiratory tract infection or exacerbation of wheezing. Subjects were requested to refrain from caffeine for 12 hours and to omit bronchodilators for 12 hours (inhalers), 24 hours (oral preparations), or 48 hours (sustained release preparations) before attendance.

Written informed consent was obtained from all subjects attending and the study was approved by the Central Manchester Health Authority ethical committee. A resting 12 lead electrocardiograph was performed, and subjects with evidence of myocardial ischaemia were excluded from methacholine challenge. 
Baseline pulmonary function was measured (Compact, Vitalograph, Buckingham, UK) using the mean of six reproducible readings. Methacholine challenge was performed only if baseline forced expiratory volume in one second $\left(\mathrm{FEV}_{1}\right)$ was $\geq 60 \%$ predicted.

Subjects completed the St George's Respiratory Questionnaire, ${ }^{8}$ which is a self-completed questionnaire validated as a measure of quality of life in subjects with chronic airways obstruction. Three component scores are calculated: Symptoms (frequency and severity), Activities (causing or limited by breathlessness), and Impacts (on employment and emotions, feelings of panic or control), as well as a total score. Higher scores indicate greater morbidity.

Methacholine challenge was performed by the Newcastle dosimeter method. ${ }^{910}$ Briefly, doubling doses of nebulised methacholine were inhaled at five minute intervals by the subject while seated and wearing a noseclip. $\mathrm{FEV}_{1}$ was measured before each subsequent dose; as recommended, three readings reproducible within $10 \%$ were performed each time and the mean was used. End points were a $20 \%$ decrease in $\mathrm{FEV}_{1}$ or administration of a maximum cumulative dose of $6.4 \mathrm{mg}$ methacholine. Results were expressed as (a) dose of methacholine producing a $20 \%$ fall from baseline $\mathrm{FEV}_{1}\left(\mathrm{PD}_{20}\right)$, and (b) the slope of the doseresponse curve to methacholine (dose-response slope) which gives a continuous non-censored measure of bronchial responsiveness expressed in units of percentage decline in $\mathrm{FEV}_{1}$ per $\mu \mathrm{g}$ methacholine. ${ }^{11}$

\section{DATA ANALYSIS}

St George's Questionnaire scores and values for the dose-response slope were log transformed to achieve normal distribution. To allow log transformation of all St George's Questionnaire scores, the value 0.5 was allocated to those subjects with scores of 0 . One subject had a slight increase in $\mathrm{FEV}_{1}$ during methacholine challenge producing a negative dose-response slope; to allow logarithmic conversion of this result a constant of 0.43 was added to all doseresponse slope values. ${ }^{12}$ Relationships between quality of life scores and pulmonary function were analysed by linear correlation and multiple regression. Subgroups were compared by grouped $t$ tests.

To avoid the age and height bias associated with the expression of $\mathrm{FEV}_{1}$ as a percentage of predicted values, baseline $\mathrm{FEV}_{1}$ was expressed as standardised residuals (SR) for calculation of correlation coefficients and multiple regression. ${ }^{13}$ These were calculated using the equation $S R=$ (recorded value-predicted value)/RSD, where RSD is the residual standard deviation about the regression equation used to calculate the predicted values. ${ }^{14}$ The prediction equations used for the calculation of standardised residuals were derived from urban white UK adults over a wide age range comparable to that of the current study. ${ }^{15}$

Chronic airways obstruction was defined as a ratio of $\mathrm{FEV}_{1}$ to forced vital capacity (FVC)

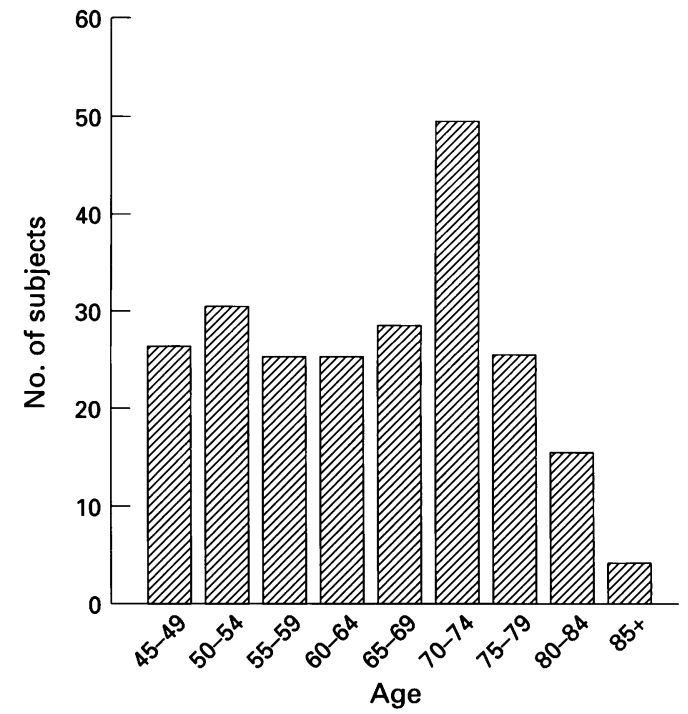

Figure 1 Age distribution of subjects performing spirometric tests.

of $<65 \%$ in those aged $<65$ years; since this ratio decreases with normal ageing, a predicted value and lower limit of normal for $\mathrm{FEV}_{1} / \mathrm{FVC}$ was calculated for subjects aged $\geq 65$ using equations from the Cardiovascular Health Study. ${ }^{16}$

Bronchial hyperresponsiveness was defined as a $\mathrm{PD}_{20}$ of $\leq 100 \mu \mathrm{g}$ methacholine; this level has been shown to have a predictive value for current asthma of nearly $100 \% .{ }^{17}$ In all cases significance was defined at the $5 \%$ level.

\section{Results}

We contacted 783 eligible subjects; 508 returned the full questionnaire and could be assessed for suitability for methacholine challenge. A further 215 subjects completed abbreviated questionnaires (overall response rate $92 \cdot 3 \%$ ). Responders were representative of the population in age and sex distribution; those completing full and abbreviated questionnaires were similar in terms of smoking history and prevalence of diagnosed asthma or bronchitis.

One hundred and thirteen subjects were excluded from methacholine challenge because of heart disease or medication; of the 395 invited to attend, 247 agreed. There was a slight age difference between attenders and non-attenders (mean age of attenders 64.5 years, non-attenders $66 \cdot 1 ; p=0.02$ ), but attenders were representative in terms of smoking habit, diagnosed asthma and bronchitis, and prevalence of respiratory symptoms.

Two hundred and twenty seven attenders performed reproducible spirometric tests and completed the St George's Questionnaire, of whom 26 had a baseline $\mathrm{FEV}_{1}$ of $<60 \%$ predicted, two had electrocardiographic evidence of ischaemic heart disease, and nine were unable to complete the methacholine challenge. Challenge results were thus available for 190 subjects.

One hundred and twenty eight of the 227 subjects who performed spirometric tests were women. The age distribution is shown in fig 1 . 


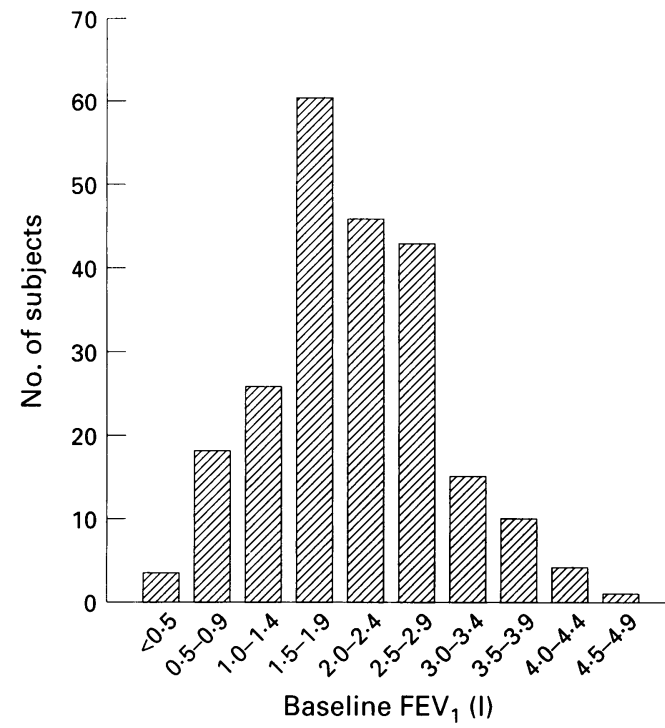

Figure 2 Distribution of baseline forced expiratory volume in one second (FEV $)$.

Seventy one subjects were current smokers and 91 were ex-smokers. Thirty three reported a previous diagnosis of asthma and 52 "bronchitis"; 33 were using inhaled bronchodilators and/or an inhaled steroid.

Figure 2 shows the distribution of baseline $\mathrm{FEV}_{1}$. Fifty nine subjects had chronic airways obstruction $\left(\mathrm{FEV}_{1} / \mathrm{FVC}\right.$ of $<65 \%$ or lower than predicted level ${ }^{16}$; the mean (SD) age of these subjects was $66 \cdot 2(10 \cdot 0)$ years (range $47-84$ ). There was no age difference between these subjects and the 168 subjects without airways obstruction (mean (SD) age 64.1 (11.2) years, range $45-86 ; t=-1 \cdot 3, p=N S$ ). Twenty five subjects with chronic airways obstruction were aged $<65$ years and 34 were aged $\geq 65$ years $\left(\chi^{2}=0 \cdot 6, p=N S\right)$.

A $\mathrm{PD}_{20}$ value was obtained in 135 subjects of whom 48 had bronchial hyperresponsiveness $\left(\mathrm{PD}_{20} \leq 100 \mu \mathrm{g}\right)$. The mean ages of subjects with and without bronchial hyperresponsiveness were similar $\left(\mathrm{PD}_{20} \leq 100 \mu \mathrm{g}\right.$ : mean $(\mathrm{SD})$ age $64.4(11.2)$, range $45-86 ; \mathrm{PD}_{20}>100 \mu \mathrm{g}$ : mean (SD) age $63.6(10.8)$, range $45-86 ; \mathrm{t}=$ $-0.4, p=N S)$. Twenty three subjects with bronchial hyperresponsiveness were aged $<65$ years and 25 were $\geq 65$ years $\left(\chi^{2}=0 \cdot 1, p=N S\right)$.

The distribution of total St George's Questionnaire scores is shown in fig 3; 16 subjects had a score of zero (indicating no quality of life impairment). Geometric mean quality of

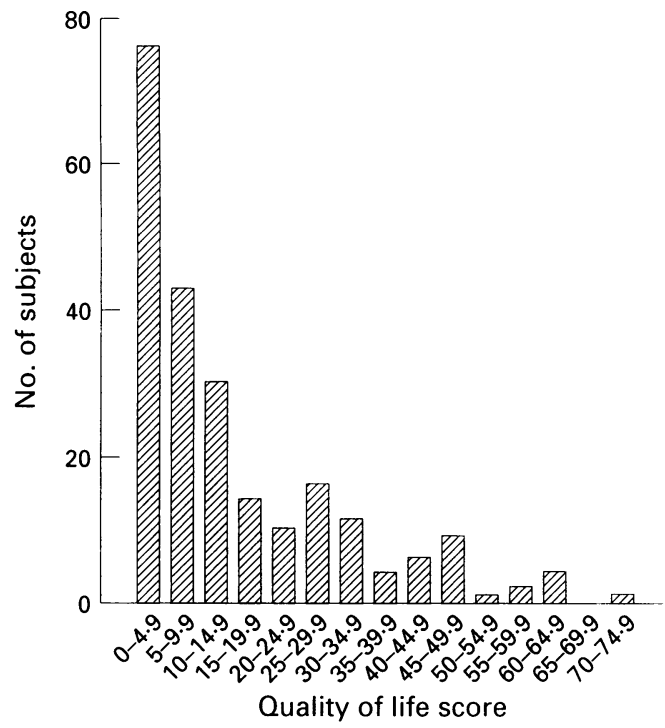

Figure 3 Distribution of total quality of life scores.

life scores were similar for men and women. There was no correlation between quality of life scores and age. However, the mean Activities score was significantly higher for subjects aged $\geq 65$ years (geometric mean (SD) $1.04(0.71))$ than for those aged $<65$ years $(0.81(0.76) ; \mathrm{t}=-2 \cdot 34, \mathrm{p}=0 \cdot 02)$.

Total quality of life scores were significantly higher in the 59 subjects with chronic airways obstruction, indicating quality of life impairment in subjects with obstructive airways disease. Similarly, all quality of life scores except the Impacts score were significantly higher in those with bronchial hyperresponsiveness (table 1).

For the whole group there was significant negative correlation between log total quality of life score and baseline $\mathrm{FEV}_{1}$ (expressed as standardised residuals) $(r=-0.47, \mathrm{p}<0.001$; fig 4). There was also a significant positive correlation between $\log$ total quality of life score and $\log$ dose-response slope $(r=0 \cdot 20$, $\mathrm{p}<0.005$; fig 5). Similar correlations were seen between baseline $\mathrm{FEV}_{1}$ (standardised residuals) and $\log$ Activities score $(r=-0.38, \mathrm{p}<0.001)$, log Impacts score $(r=-0.47, \mathrm{p}<0.001)$ and $\log$ Symptoms score $(r=-0 \cdot 37, \mathrm{p}<0 \cdot 001)$, and between the log dose-response slope and log Activities score $(r=0 \cdot 18, \mathrm{p}<0 \cdot 01), \log$ Impacts score $(r=0.17, \mathrm{p}<0.01)$, and log Symptoms score $(r=0 \cdot 23, \mathrm{p}=0.001)$.

Table 1 Geometric mean (SD) quality of life scores in subjects with and without chronic airways obstruction and bronchial hyperresponsiveness

\begin{tabular}{|c|c|c|c|c|}
\hline & Total score & Activities score & Impacts score & Symptoms score \\
\hline \multirow{3}{*}{$\begin{array}{l}\text { Subjects with chronic airways } \\
\text { obstruction } \\
\text { Subjects without chronic airways } \\
\text { obstruction }\end{array}$} & $1.18(0.49)$ & $1 \cdot 18(0.65)$ & $0 \cdot 76(0 \cdot 73)$ & $1.41(0.56)$ \\
\hline & $0.84(0.53)$ & $0 \cdot 85(0.75)$ & $0 \cdot 34(0.69)$ & $0.92(0.77)$ \\
\hline & $\begin{array}{l}t=-4 \cdot 2 \\
p<0 \cdot 0001\end{array}$ & $\begin{array}{l}\mathrm{t}=-3.0 \\
\mathrm{p}<0.005\end{array}$ & $\begin{array}{l}t=-3.9 \\
p=0.0001\end{array}$ & $\begin{array}{l}t=-4.5 \\
p<0.0001\end{array}$ \\
\hline \multirow{3}{*}{$\begin{array}{l}\text { Subjects with bronchial } \\
\text { hyperresponsiveness } \\
\text { Subjects without bronchial } \\
\text { hyperresponsiveness }\end{array}$} & $0.98(0.47)$ & $1.03(0.64)$ & $0 \cdot 39(0 \cdot 70)$ & $1 \cdot 21(0 \cdot 70)$ \\
\hline & $0.81(0.51)$ & $0 \cdot 80(0 \cdot 73)$ & $0 \cdot 29(0 \cdot 70)$ & $0.89(0 \cdot 74)$ \\
\hline & $\begin{array}{l}\mathrm{t}=-2.0 \\
\mathrm{p}=0.05\end{array}$ & $\begin{array}{l}\mathrm{t}=-1.9 \\
\mathrm{p}=0.05\end{array}$ & $\begin{array}{l}\mathrm{t}=-0 \cdot 9 \\
\mathrm{p}=\mathrm{NS}\end{array}$ & $\begin{array}{l}t=-2 \cdot 6 \\
p=0.01\end{array}$ \\
\hline
\end{tabular}




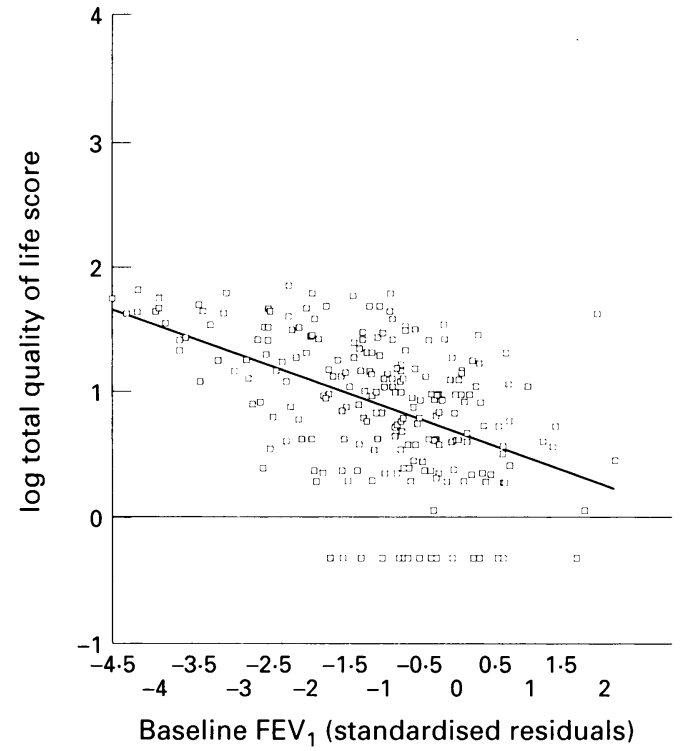

Figure 4 Relationship between total quality of life score and baseline $F E V_{1}$ (standardised residuals).

Multiple regression analysis was performed with quality of life score as the dependent variable and baseline $\mathrm{FEV}_{1}$, log dose-response slope, age, and sex as independent variables. As there was a significant correlation between the baseline $\mathrm{FEV}_{1}$ and log dose-response slope, an interaction term was included in the regression $^{12}$; this was not significantly related to quality of life in any of the analyses. For the whole subject group, both total and separate component quality of life scores showed independent negative relationships with baseline $\mathrm{FEV}_{1}$ (standardised residuals); only the Symptoms score showed a significant association with the log dose-response slope (table 2).

The effect of smoking on quality of life was assessed by comparing total St George's Ques-

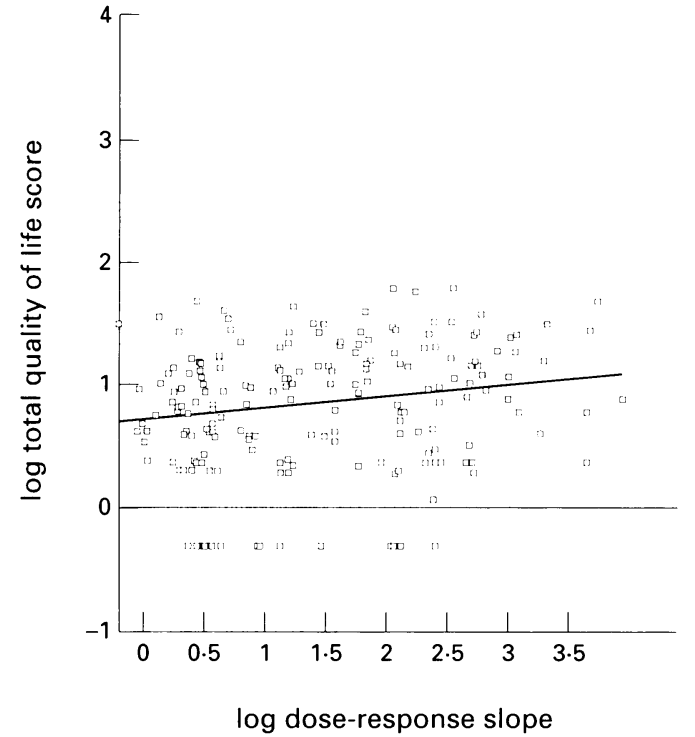

Figure 5 Relationship between total quality of life score and $\log$ dose-response slope.

tionnaire scores of never smokers and smokers (ex-smokers plus current smokers). Quality of life was significantly impaired in smokers (total score $10 \cdot 3(3 \cdot 2)$ versus $5 \cdot 6(3 \cdot 9) ; \mathrm{t}=-3 \cdot 3$, $\mathrm{p}=0 \cdot 001$ ). When smoking status (current, exsmoker, or never smoker) was added to the multiple regression for the whole subject group, the total quality of life score was found to be significantly associated with smoking status as well as baseline $\mathrm{FEV}_{1}$. However, because of the interrelationship between $\mathrm{FEV}_{1}$ and smoking status, it was necessary to include an interaction term in the regression. When this was added it was significantly associated with quality of life score, and the relationship between quality of life score and smoking status itself was no longer significant, indicating that the effect of

Table 2 Factors associated with quality of life scores: multiple regression analysis

\begin{tabular}{|c|c|c|c|c|}
\hline & $\begin{array}{l}\text { Log total } \\
\text { score }\end{array}$ & $\begin{array}{l}\text { Log activities } \\
\text { score }\end{array}$ & $\begin{array}{l}\text { Log impacts } \\
\text { score }\end{array}$ & $\begin{array}{l}\text { Log symptoms } \\
\text { score }\end{array}$ \\
\hline $\mathrm{FEV}_{1}$ (standardised residuals) & $\begin{array}{l}B=-0.15 \\
S E=0.04 \\
p<0.0001\end{array}$ & $\begin{array}{l}B=-0.18 \\
S E=0.05 \\
p<0.001\end{array}$ & $\begin{array}{l}B=-0.16 \\
S E=0.05 \\
p<0.002\end{array}$ & $\begin{array}{l}B=-0.13 \\
S E=0.06 \\
p<0.05\end{array}$ \\
\hline Log dose-response slope & $\begin{array}{l}B=0 \cdot 04 \\
S E=0 \cdot 04 \\
p=N S\end{array}$ & $\begin{array}{l}B=0.06 \\
S E=0.06 \\
p=N S\end{array}$ & $\begin{array}{l}B=0.06 \\
S E=0.05 \\
p=N S\end{array}$ & $\begin{array}{l}B=0.11 \\
S E=0.06 \\
p=0.05\end{array}$ \\
\hline Age & $\begin{array}{l}B=0 \cdot 0003 \\
S E=0.003 \\
p=N S\end{array}$ & $\begin{array}{l}B=0.0003 \\
S E=0.005 \\
p=N S\end{array}$ & $\begin{array}{l}B=0.002 \\
S E=0.004 \\
p=N S\end{array}$ & $\begin{array}{l}B=-0.006 \\
S E=0.005 \\
p=N S\end{array}$ \\
\hline Sex & $\begin{array}{l}\mathrm{B}=-0.05 \\
\mathrm{SE}=0.07 \\
\mathrm{p}=\mathrm{NS} \\
R^{2}=0.08\end{array}$ & $\begin{array}{l}\mathrm{B}=-0 \cdot 16 \\
\mathrm{SE}=0 \cdot 1 \\
\mathrm{p}=\mathrm{NS} \\
R^{2}=0.05\end{array}$ & $\begin{array}{l}\mathrm{B}=0.02 \\
\mathrm{SE}=0.01 \\
\mathrm{p}=\mathrm{NS} \\
R^{2}=0.05\end{array}$ & $\begin{array}{l}\mathrm{B}=0 \cdot 10 \\
\mathrm{SE}=0 \cdot 1 \\
\mathrm{p}=\mathrm{NS} \\
R^{2}=0 \cdot 07\end{array}$ \\
\hline
\end{tabular}

Table 3 Correlation between quality of life scores and bronchial responsiveness, and between quality of life scores and baseline forced respiratory volume in one second (FEV $)$ in older and younger subjects

\begin{tabular}{lllll}
\hline & $\begin{array}{l}\text { Log total } \\
\text { score }\end{array}$ & $\begin{array}{l}\text { Log activities } \\
\text { score }\end{array}$ & $\begin{array}{l}\text { Log impacts } \\
\text { score }\end{array}$ & $\begin{array}{l}\text { Log symptoms } \\
\text { score }\end{array}$ \\
\hline $\begin{array}{l}\text { Log dose-response slope } \\
\text { Age }<65\end{array}$ & $r=0.31$ & & & $r=0.30$ \\
& $\mathrm{p}=0.001$ & $\mathrm{p}<0.27$ & $r=0.33$ & $\mathrm{p}=0.001$ \\
Age $\geq 65$ & $r=0.08$ & $r=0.07$ & $\mathrm{p}<0.001$ & $r=0 \cdot 16$ \\
& $\mathrm{p}=\mathrm{NS}$ & $\mathrm{p}=\mathrm{NS}$ & $\mathrm{p}=0.01$ & $\mathrm{p}=\mathrm{NS}$ \\
FEV & & $r=-0.35$ & $r=-0.41$ & $r=-0.31$ \\
Age $<65$ & $r=-0.42$ & $\mathrm{p}<0.001$ & $\mathrm{p}<0.001$ & $r<0.001$ \\
Age $\geq 65$ & $\mathrm{p}<0.001$ & $r=-0.40$ & $r=0.51$ & 0.42 \\
& $r=-0.51$ & $\mathrm{p}<0.001$ & $\mathrm{p}<0.001$ & $\mathrm{p}<0.001$ \\
\hline
\end{tabular}


smoking status on quality of life was the result of the interaction between smoking and $\mathrm{FEV}_{1}$, rather than an independent effect.

The effect of age on the relationship between quality of life and lung function was assessed by repeating the analysis with the subjects divided into two age groups: $<65$ years $(n=106)$ and $\geq 65$ years $(n=121)$. Calculation of linear correlation coefficients for the two groups gave similar results to those for the whole group, except that in the older age group there was no correlation between the log dose-response slope and quality of life scores (table 3 ). However, multiple regression analysis revealed differences between the age groups: in subjects aged $<65$ years the total quality of life score was significantly associated with the log doseresponse slope $(B=0 \cdot 17, S E=0.05, p<0.001)$ but not baseline $\mathrm{FEV}_{1}(\mathrm{~B}=-0.08, \mathrm{SE}=0.06$, $\mathrm{p}=\mathrm{NS}$ ), whereas in the older group the opposite was true (log dose-response slope: $\mathrm{B}=-0 \cdot 02, \mathrm{SE}=0 \cdot 05, \mathrm{p}=\mathrm{NS}$; baseline $\mathrm{FEV}_{1}$ : $\mathrm{B}=-0 \cdot 18, \mathrm{SE}=0 \cdot 05, \mathrm{p}=0 \cdot 0005)$.

\section{Discussion}

Our results confirm that obstructive airways disease impairs quality of life. We have found no relationship between quality of life and age or sex, but have shown significant relationships with baseline $\mathrm{FEV}_{1}$ and with non-specific bronchial responsiveness. Both chronic airways obstruction and bronchial hyperresponsiveness were relatively common in our population. This may reflect the large numbers of current and ex-smokers in this inner city area. However, smoking status itself was not found to be independently associated with quality of life.

Although the relationships between $\mathrm{FEV}_{1}$ and quality of life scores were statistically significant, the value of $R^{2}$ for the multiple regression calculations was low, indicating that variation in $\mathrm{FEV}_{1}$ explains only a small amount of the variation in quality of life. This weak relationship between quality of life and lung function indices in patients with airways obstruction has been previously reported, ${ }^{2-5}$ and has led to the suggestion that variability between patients in perception of breathlessness is a more important determinant of disability than the degree of airways obstruction itself. ${ }^{18}$ Psychological assessment of patients with obstructive airways disease has shown that illness attitudes and beliefs are stronger predictors of breathlessness and exercise tolerance than are measures of airways obstruction. ${ }^{1920}$

Although perhaps under-rated by doctors as a cause of distress, our results show that airways obstruction is associated with significant emotional dysfunction and limitation of activities. This impact of respiratory symptoms on activity was highlighted by a large population survey of elderly people in $1976^{21}$ in which $17 \%$ of housebound individuals or those confined to bed identified "pulmonary conditions" as the cause of their immobility and were second only to "arthritis, rheumatism" as the most common factor reducing independence.

The St George's Questionnaire is a diseasespecific quality of life score designed for use in subjects with airways obstruction. As such, it has not been validated in a general population sample. In the current study subjects with no airways disease tended to record very low quality of life impairment, particularly for the Symptoms score. This produced a skewed distribution of quality of life scores. St George's Questionnaire scores have been shown to be independent of age in subjects aged up to 75 years, ${ }^{8}$ but the questionnaire has not been validated in older subjects. The lack of correlation between quality of life scores and age in the current study suggests that the questionnaire is also valid in the elderly. However, the mean Activities score was higher for older subjects, indicating reduced activity levels with age.

Interestingly, where other studies have shown a change in quality of life with increasing age in subjects with asthma or obstructive airways disease, this has generally been an improvement in quality of life in older subjects. ${ }^{3-6}$ This has led to the suggestion that older subjects may be more tolerant of the effects of airways obstruction due to a reduction in their normal activity levels or in their expectations of life. It has been shown that older adults describe less severe symptoms than younger adults when exposed to the same degree of methacholineinduced bronchoconstriction. ${ }^{22}$ However, there is no evidence for a general decrease in the reporting of distressing symptoms by the elderly - indeed the opposite may be true. ${ }^{23}$ The results of the current study do not confirm a reduction in the impact of obstructive airways disease on quality of life in older people.

Our results show that the interrelationships between bronchial responsiveness, baseline $\mathrm{FEV}_{1}$, and quality of life scores change with age. The reasons for this are not clear. Mortagy et al have described a cluster of respiratory symptoms representing "bronchial irritability" which are associated with increased bronchial responsiveness in young adults. ${ }^{24}$ However, the predictive value of these symptoms for increased bronchial responsiveness is much lower in the elderly. ${ }^{1}$ Since respiratory symptoms affect quality of life, the lack of "bronchial irritability" symptoms in older adults with increased bronchial responsiveness may reduce the strength of the relationship between bronchial responsiveness and quality of life in this age group. Alternatively, our results may reflect a change in the interaction between baseline $\mathrm{FEV}_{1}$ and bronchial responsiveness with age, rather than a change in their interaction with quality of life.

Schrier et al have also shown that obstructive airways disease is associated with impairment of quality of life in adults over a wide age range. ${ }^{2}$ However, it is not clear whether quality of life was related to age in this study. The influence of increased bronchial responsiveness on quality of life was studied in young asthmatics by Malo et $a l^{25}$ who found the mean quality of life score to be weakly but significantly correlated with baseline $\mathrm{FEV}_{1}$ and non-specific bronchial responsiveness, as in the current study. 
In summary, we have measured quality of life, airways calibre, and non-specific bronchial responsiveness in a population sample over a wide age range and have shown significant correlations between quality of life and both baseline $\mathrm{FEV}_{1}$ and non-specific bronchial responsiveness. Multiple regression showed a significant independent relationship between quality of life and $\mathrm{FEV}_{1}$ in older subjects, and between quality of life and non-specific bronchial responsiveness in younger subjects. However, the amount of variability in quality of life attributable to changes in $\mathrm{FEV}_{1}$ and nonspecific bronchial responsiveness is small. The impact of obstructive airways disease on quality of life does not decrease with advancing age.

The authors wish to thank the British Geriatrics Society and Central Manchester Healthcare Trust for funding this project, the Institute of Clinical Physiology at Manchester Royal Infirmary for the loan of equipment, and Acorn Nebulisers Ltd for supplying nebulisers. We are also indebted to the following general practitioners for allowing us to study their patients: $\mathrm{Dr}$ P Beresford, Dr S Elliot, Dr P Harris, Dr S Hilton, Dr A Hutton, Dr H MacDonald, Dr L Reynolds, and Dr I Sethi.

1 Dow L, Coggon D, Holgate ST. Respiratory symptoms as predictors of airways lability in an elderly population. Respir Med 1992;86:27-32.

2 Schrier AC, Dekker FW, Kaptein AA, Dijkman JH. Quality of life in elderly patients with chronic nonspecific lung of life in elderly patients with chronic nonspecific
disease seen in family practice. Chest 1990;98:894-9.

3 Guyatt GH, Townsend M, Berman LB, Pugsley SO. Quality of life in patients with chronic airflow limitation. $\mathrm{Br} \mathcal{F} \mathrm{Dis}$ Chest 1987;81:45-54.

4 Quirk FH, Baveystock CM, Wilson R, Jones PW. Influence of demographic and disease related factors on the degree of distress associated with symptoms and restrictions on daily living due to asthma in six countries. Eur Respir $\mathcal{f}$ 1991;4:167-71.

5 Quirk FH, Jones PW. Patients' perception of distress due to symptoms and effects of asthma on daily living and an investigation of possible influential factors. Clin Sci 1990 79:17-21.

6 Juniper EF, Guyatt GH, Epstein RS, Ferrie PJ, Jaeschke R, Hiller TK. Evaluation of impairment of health related quality of life in asthma: development of a questionnaire quality of life in asthma: development of a ques
for use in clinical trials. Thorax 1992;47:76-83.

7 Sherman CB, Tollerud DJ, Heffner LJ, Speizer FE, Weiss ST. Airway responsiveness in young black and white women. Am Rev Respir Dis 1993;148:98-102.
8 Jones PW, Quirk FH, Baveystock CM, Littlejohns P. A selfcomplete measure of health status for chronic airflow limitation. The St. George's Respiratory Questionnaire. Am Rev Respir Dis 1992;145:1321-7.

9 Connolly MJ, Avery AJ, Walters EH, Hendrick DJ. The relationship between non-specific bronchial responsiveness to methacholine and histamine in asthmatic subjects. Pulm Pharmacol 1988;1:53-8.

10 Connolly MJ, Kelly C, Walters EH, Hendrick DJ. An assessment of methacholine inhalation tests in elderly asthmatics. Age Ageing 1988;17:123-8.

11 O'Connor G, Sparrow D, Taylor D, Segal M, Weiss S. Analysis of dose-response curves to methacholine. An analysis of dose-response curves to methacholine. An Dis $1987 ; 136: 1412-7$.

12 Sparrow D, O'Connor GT, Rosner B, Weiss ST. Predictors of longitudinal change in methacholine airway responsiveness among middle-aged and older men. The Normative Aging Study. Am 7 Respir Crit Care Med 1994; 149:376-81.

13 Miller MR, Pincock AC. Predicted values: how should we use them? Thorax 1988;43:265-7.

14 Miller MR, Pincock AC, Grove DM. Patterns of spirogram abnormality in individual smokers. Am Rev Respir Dis 1985;132:1034-40.

15 Roberts CM, MacRae KD, Winning AJ, Adams L, Seed WA. Reference values and prediction equations for normal lung function in a non-smoking white urban population. Thorax 1991;46:643-50.

16 Enright PL, Kronma RA, Higgins M, Schenker M, Haponik EF. Spirometry reference values for women and men aged 65 to 85 years of age. Cardiovascular Health Study. $A m$ Rev Respir Dis 1993;147:125-33.

17 Cockcroft DW, Killian DN, Mellon JJA, Hargreave FE Bronchial reactivity to inhaled histamine: a method and clinical survey. Clin Allergy 1977;7:235-43.

18 Jones PW. Quality of life measurement for patients with diseases of the airways. Thorax 1991;46:676-82.

19 King B, Cotes JE. Relation of lung function and exercise capacity to mood and attitudes to health. Thorax 1989; 44:402-9.

20 Morgan AD, Peck DF, Buchanan DR, McHardy GJR. Effect of attitudes and beliefs on exercise tolerance in chronic bronchitis. BMf 1983;286:171-3.

21 Hunt A. The elderly at home. A study of people age sixty five and over living in the community in England in 1976. OPCS Social Survey Division, London: HMSO, 1976.

22 Connolly MJ, Crowley JJ, Charan NB, Nielson CP, Vestal RE. Reduced subjective awareness of bronchoconstriction provoked by methacholine in elderly asthmatic and normal subjects as measured on a simple awareness scale. Thorax 1992;47:410-3.

23 Woods RT, Britton PG. Clinical psychology with the elderly. Beckenham, Kent: Croom Helm, 1985:59.

24 Mortagy AK, Howell JBL, Waters WE. Respiratory symptoms and bronchial reactivity: identification of a syndrome toms and bronchial reactivity: identification of a syn

25 Malo JL, Boulet LP, Dewitte JD, et al. Quality of life of subjects with occupational asthma. $\mathcal{F}$ Allergy Clin Immunol 1993;91:1121-7. 